\title{
PREVALENCE AND CHARACTERISTICS ASSOCIATED WITH ALCOHOL USE AND ALCOHOL RELATED PROBLEMS IN COMMUNITY DWELLING OLDER ADULTS
}

\author{
Y. van Gils ${ }^{1,2}$, E. Franck ${ }^{2}$, S.J.P. van Alphen ${ }^{1,3,4,5,6}$, E. Dierckx $x^{1,7}$
}

\begin{abstract}
Objective: This study examine the prevalence, characteristics and associated factors of alcohol use and alcohol related problems among Belgian community dwelling older adults. Design: Retrospective cross-sectional study by extensive examination survey. Setting: The participants were questioned in their homes or in community centres. Participants: Overall, 1,366 adults $\geq 65$ years participated in this study. Method: Information about self-reported alcohol use during the past year, Health Related Quality of Life (HRQL) and alcohol related problems was gathered with respectively the AUDIT, SF36 and MAST-G. Results: Of the total sample, $84.4 \%$ reported alcohol consumption. Using the NIAAA guidelines, the overall prevalence for at risk drinking was $26.6 \%$ and for binge drinking $14.8 \%$, both risky alcohol patterns. Logistic regression analyses were performed on the drinking sample to determine the predictors associated with at risk drinking, binge drinking and hazardous drinking. Being male, a smoker of former smoker and living alone were associated with at risk drinking. Being male, being aged 65-74 years, being a smoker, reporting polypharmacy, MCS and having recent loss experience were associated with binge drinking. More than $25 \%$ of respondents were classified as hazardous drinking (score $\geq 5$ on MAST-G). Associated factors with hazardous drinking were being male, having a family history of alcohol problems, PCS and MCS. Conclusions: The prevalence rates for at risk alcohol patterns and alcohol related problems were higher than in previous studies. As older adults are more vulnerable to the adverse consequences of alcohol use, awareness about alcohol use should be raised among older adults, as well as amongst health care givers and researchers.
\end{abstract}

Key words: Older adults, alcohol use, alcohol related problems.

\section{Introduction}

In Europe the use of alcoholic beverages is widespread and commonly accepted. Due to the destigmatization during the last decades, alcohol has become part of the European culture. Despite results of longitudinal studies about decrease in alcohol consumption among older adults $(1,2)$, alcohol use by older adults seems more prevalent than generally assumed (3-6). Based on European data, the prevalence among older adults was approximately $57 \%$ ranging from $44 \%$ to $80 \%$ (5, 7-11). Older male adults seemed to consume more

1. University of Brussels, Faculty of Psychology and Educational Science, Pleinlaan 2, 1050 Elsene, Belgium; 2. University of Antwerp, Faculty of Medicine and Social Science, Universiteitsplein 1, 2610 Wilrijk, Belgium; 3. Tilburg University, School of Social and Behavioural Sciences, Department of Medical and Clinical Psychology, Warandelaan 2, Tilburg, The Netherlands; 4. Professor of Clinical Geropsychology at Faculty of Psychology \& Educational Sciences, Department of Clinical \& Lifespan Psychology, Vrije Universiteit Brussel (VUB), Brussels, Belgium; 5. Manager of the Clinical Center of Excellence for Personality Disorders in Older Adults, Mondriaan Hospital, Heerlen-Maastricht, The Netherlands; 6. Professor of Health Care Psychology at School of Social and Behavioral Sciences, Department of Medical and Clinical Psychology, Tilburg University, Tilburg, The Netherlands; 7. Alexianen Zorggroep Tienen, Psychiatric Hospital

Corresponding Author: Y. van Gils, University of Brussels, Faculty of Psychology and Educational Science, Pleinlaan 2, 1050 Elsene, Belgium, yannic.vangils@ uantwerpen.be alcohol compared to older females (11-13). Living with someone, being younger than 80 (12-14) and having a higher educational level $(5,12)$ were associated with more alcohol consumption among older adults. According to Geels et al. (2013) a higher prevalence in alcohol use among the population of older adults might also be due to the increasing amount of healthy life years in combination with a higher average income.

Alcohol use among older adults carries risks since older adults are more vulnerable to the adverse consequences. Biological as well as psychological and social problems have been reported. Cancers, like liver and pharynx cancers, cardiovascular disease, liver disease $(15,16)$, more severe functional problems and even mortality $(11,17,18)$ have been associated in older adults with excessive drinking. Also, at risk drinking is associated with the tendency for injuries (16, 19) and falling (20). In addition, older people reported using multiple medication more frequently than their younger peers. This will expose them to greater risks because of the possible adverse interaction between alcohol and medication (12). Within the psychological domain, stressful life events (13) and an increased risk for depressive and anxiety symptoms $(12,21,22)$ frequently co-occurred. Finally, alcohol use in older adults may 
have an impact on their social context. Spouses of older adults with alcohol related problems showed more health problems, emotional problems and depressive symptoms and were less involved in social activities (23, 24). Moreover, at risk drinking was associated with social isolation $(22,25)$.

Given the higher vulnerability for these negative consequences of alcohol, the National Institute for Alcohol Abuse and Alcoholism (NIAAA) developed guidelines for safe alcohol use especially for this population of older adults. The NIAAA describes the maximum drink limits for adults 65 years and older as 'drinking no more than three drinks per day and no more than seven drinks in a week'. Drinking more than three drinks per day or more than seven in a week has been considered as risky drinking behaviour. Binge drinking means, for men and women respectively, drinking five and four or more units during one occasion (18). Prevalence figures of at risk alcohol use in Europe are variable. Immonen et al. (2013)reported that $6.4 \%$ of their Finish community dwelling older adults were classified as at risk drinkers, whereas Cousins et al. (2014)reported in a population based sample of older Irish adults almost $20 \%$ at risk drinkers. This variation is largely due to the use of different methods of assessment and the lack of consistency in the definition of 'at risk drinking' in older adults (27). In general, there is a shortage of data on alcohol use among older adults in Europe (28). Also in Belgium knowledge about the prevalence of alcohol use among older adults is limited. Nevertheless alcohol use among community dwelling older adults across the world is rising. According to a longitudinal study in the United States, the prevalence of binge drinking and alcohol use disorders among older adults is significantly increasing. There was a relative increase of $19.2 \%$ for binge drinking and a $23.3 \%$ relative increase for alcohol use disorders over the last decade. This increase of unhealthy drinking was significant for both men and women (29). The burden on our health care and on the health of drinking older adults is substantial and may grow the following years as the babyboom generation ages (12). Awareness of the use of alcohol in this population and the associated factors seems necessary in order to provide relevant and adapted prevention programs and interventions and to reduce the negative consequences. In previous studies, the following associated factors with at risk drinking have already been identified. Adults older than 65 years of age in the at risk drinking group were more likely to be men $(13,30,31)$, having a higher educational level $(19,31)$, suffering from depression (32) having a history of alcoholism in the family (13), were currently smoking $(13,19,31)$ and were younger than 80 years of age $(19,30)$.

As older adults make up the fastest growing segment of the population, monitoring their alcohol consumption will be increasingly important, including in our Northern part of Belgium (Flanders). Therefore, the aim of this study is:

1. To describe the prevalence of a. non-drinking, drinking within the guidelines and at risk drinking, $b$. binge drinking and c. hazardous drinking among older adults in Flanders.

2. To describe the characteristics of a. non-drinking, drinking within the guidelines and at risk drinking, $b$. binge drinking and c. hazardous drinking among older adults in Flanders.

3. To determine the associated factors of a. at risk drinking, $b$. binge drinking and c. hazardous drinking among older adults in Flanders.

\section{Methods}

This is a retrospective crosssectional study exploring alcohol use and associated factors in community dwelling older adults by using an extensive quantitative survey.

\section{Sample}

Adults aged 65 or older and living at home were invited to participated. Older adults reporting memory problems, having a neurodegenerative disease or sensory deficits were excluded. As the questionnaire was in Dutch, older adults needed to have a good comprehension of the Dutch language. If they reported difficulties understanding the questions due to language problems, they were also excluded.

The sample population, enrolled from October 2013 to April 2016, consisted of 1,368 older adults living in the Flemish part of Belgium (Flanders). This study is part of a larger research project on the drinking patterns of older adults in Belgium.

The population was recruited by a snowball sampling. During gatherings in community centres and local activity groups the purpose and procedure of the study were explained. Subjects were able to sign up and those who did were asked to make an appointment. The appointments were made at their own residence. At that time, a trained research assistant explained the purpose and procedure of the study for a second time. Most older adults were able to complete the questionnaire by themselves, yet the research assistant was at all time available for help and assistance. When both spouses were questioned, they were placed in different rooms of the residence to reduce potential influences. After the assessment, participants were asked if they had acquaintances that would volunteer to fill in the questionnaire. When contacting these acquaintances, only a small number of eligible participants refused to participate, mostly due to the length of the questionnaire.

\section{Measurements}

\section{Sociodemographics}

The following variables were included: age, gender, educational level (lower then primary school, lower 
secondary, high secondary, higher education bachelor degree or higher), living arrangement (widowhood, living alone, living together), loss of a loved one in previous year and family history of alcohol problems. The population was categorized into three age groups: the 'younger older adults' from 65 to 74 years of age, the 'older adults' from 75 to 84 years of age and the 'older older adults' $\geq 85$ years of age.

\section{Alcohol use}

To define alcohol use, two category systems were used. Firstly, participants were categorized as 1. nondrinkers, 2. drinkers within the guidelines or 3. at risk drinkers. 'Non-drinkers' were defined by using two questions: 'How often do you drink alcohol' and 'How much alcohol do you drink on a typical day?'. Those questions were based on the first two questions of the Alcohol Use Disorder Identification Test (AUDIT) (33). Respondents answering both questions with 'never' and 'none' respectively were categorized as non-drinkers. Since there are no specific guidelines for safe alcohol use for older adults in Belgium (www.vad.be) the NIAAA guidelines (18) were used. According to these guidelines 'at risk drinking' was defined as exceeding three units a day or seven units a week. Drinking three or less units per day and drinking seven or less units per week was considered as 'drinking within the guidelines'. Secondly, participants were categorized as non-binge drinkers or binge drinkers. 'Heavy episodic drinking' or 'binge drinking' for men was defined as drinking five or more alcohol units on the same occasion at least one day per month. For women, binge drinking was defined as more than four units on the same occasion. For this study a standard drink consisted of 10 gram of alcohol (www. vad.be).

\section{Alcohol related problems}

The geriatric version of the Michigan Alcohol Screening Test (MAST-G) was used to register selfreported alcohol problems (34). The MAST-G is a suitable screening instrument for older people in a wide range of settings including clinical settings (34-36) and a general population with a sensitivity of $94 \%$ and a specificity of $78 \%(34,37)$. This questionnaire consists of 24 items requiring a yes or no answer. The generally accepted cut off value is positively answering five or more items, indicating hazardous drinking (MAST-G score $\geq 5$ ). The MAST-G screens current alcohol use and reports the alcohol related problems experienced within the past year (34).

Health related factors: The Medical Outcome Study 36-items Short Form (SF36) was used to determine the health related quality of life (HRL) (38). The SF-36 scores were summarized using two constructs: physical component summary (PCS) and mental component summary (MCS). Both constructs were based on the eight domains of the SF-36. PCS and MCS scores are represented on a standardized scale with a mean of 50 and a standard deviation of 10 . Higher scores reflect better HRQL (39). Research from Mishra et al. (2011) suggested that the SF-36 questionnaire is an adequate measure for the health perception of an older population. The internal consistency exceeded the minimum standard of 0.80 for both components. Furthermore, the test-retest reliability was proven to be excellent and the construct validity was considerable $(38,40,41)$.

Also data on current medication and tobacco use were collected. Participants were asked whether they have taken any prescription and over-the-counter medications. Masnoon et al. (2017) conducted a systematic review on definitions for polypharmacy. According to their findings, the most commonly used definition for polypharmacy is using five or more medications. Consequently, their definition was implemented in this study for polypharmacy. Tobacco use was assessed by asking the participant if they were current, former or non- smokers.

\section{Statistical analyses}

For the statistical analyses the following category systems were used: 1 . non-drinkers, drinking within the guidelines versus at risk drinking, 2. non-binge versus binge drinking and 3. non-hazardous versus hazardous drinking.

We conducted bivariate analyses (Chi-square tests for nominal and categorical variables and independent sample t-test or one way ANOVA's (with Bonferroni correction for multiple comparisons) for continuous variables) to identify the sociodemographic and health related factors of the different category systems mentioned above.

Three binary logistic regression analyses were used to identify predictors associated with 1 . at risk drinking, 2 . binge drinking and 3 . hazardous drinking. The sample size for the binary logistic regressions were based on the subsample of drinkers. All the demographic and health related factors were included as covariates in the three different models. Adjusted odds rations (OR) with 95\% confidence intervals (CI) are presented. (43).

The statistical analyses were conducted using SPSS 25.0

\section{Statements of ethical approval}

This research did receive ethical approval from the Ethical Committee of Middelheim Hospital in Antwerp, reference OG 031; 009. Anonymity and confidentiality were emphasized by the interviewer. A written informed consent was obtained before starting the survey: no names were registered and all the obtained data were processed by the research team. 
Table 1

Prevalence and characteristics of non-drinking, drinking within the guidelines and at risk drinking among older adults

\begin{tabular}{|c|c|c|c|c|c|c|c|c|c|}
\hline & total sample & & non drinkers & & $\begin{array}{l}\text { drinking within } \\
\text { the guidelines }\end{array}$ & & $\begin{array}{c}\text { At Risk } \\
\text { drinking }\end{array}$ & & \\
\hline & $\mathbf{N}$ & $\%$ & $\mathbf{N}$ & $\%$ & $\mathbf{N}$ & $\%$ & $\mathbf{N}$ & $\%$ & $\mathrm{p}$ \\
\hline TOTAL POPULATION & 1366 & & 212 & 15.6 & 788 & 57.8 & 362 & 26.6 & \\
\hline \multicolumn{10}{|l|}{ DEMOGRAPHICS } \\
\hline GENDER & & & & & & & & & $<.001^{*}$ \\
\hline women & 761 & 55.8 & 151 & 20 & 476 & 63 & 129 & 17.1 & \\
\hline men & 605 & 44.2 & 61 & 10.1 & 311 & 51.5 & 232 & 38.4 & \\
\hline AGE & & & & & & & & & $<.001^{*}$ \\
\hline young older adults (65-74) & 831 & 60.8 & 117 & 14.1 & 457 & 55.3 & 253 & 30.6 & \\
\hline older adults (75-84) & 459 & 33.6 & 76 & 16.6 & 289 & 63.1 & 93 & 20.3 & \\
\hline older old adults (85+) & 77 & 5.6 & 19 & 25 & 41 & 53.9 & 16 & 21.1 & \\
\hline LIVING SITUATION & & & & & & & & & $<.001^{*}$ \\
\hline living alone & 92 & 8.4 & 22 & 18.2 & 56 & 46.3 & 43 & 35.5 & \\
\hline with partner & 829 & 76,0 & 133 & 13.3 & 589 & 58.8 & 279 & 27.9 & \\
\hline widowhood & 170 & 15.6 & 55 & 23.6 & 140 & 60.1 & 38 & 16.3 & \\
\hline EDUC LEVEL & & & & & & & & & $<.001^{*}$ \\
\hline primary school or lower & 27 & 2,0 & 8 & 29.6 & 11 & 40.7 & 8 & 29.6 & \\
\hline lower secondary & 441 & 32.3 & 85 & 19.3 & 262 & 59.5 & 93 & 21.1 & \\
\hline higher secondary & 479 & 35.1 & 83 & 17.5 & 274 & 57.7 & 118 & 24.8 & \\
\hline higher education & 417 & 30.6 & 35 & 8.4 & 239 & 57.5 & 142 & 34.1 & \\
\hline RECENT LOSS & & & & & & & & & $.825^{*}$ \\
\hline no & 1055 & 77.3 & 167 & 15.9 & 605 & 57.5 & 281 & 26.7 & \\
\hline yes & 309 & 22.7 & 45 & 14.8 & 181 & 59.3 & 79 & 25.9 & \\
\hline FAMILY HISTORY OF ALCOHOL PROB & & & & & & & & & $.240^{*}$ \\
\hline no & 1094 & 80.1 & 175 & 16.1 & 633 & 58.2 & 280 & 25.7 & \\
\hline yes & 271 & 19.9 & 35 & 12.9 & 155 & 57.2 & 81 & 29.9 & \\
\hline \multicolumn{10}{|l|}{ ALCOHOL USE } \\
\hline \multicolumn{10}{|l|}{ NIAAA } \\
\hline drinking within the guidelines & 788 & 57.8 & & & & & & & \\
\hline at risk drinking & 362 & 26.6 & & & & & & & \\
\hline \multicolumn{10}{|l|}{ HEALTH RELATED FACTORS } \\
\hline SMOKING & & & & & & & & & $<.001^{*}$ \\
\hline never & 770 & 56.3 & 151 & 19.7 & 470 & 61.4 & 144 & 18.8 & \\
\hline yes & 132 & 9.6 & 14 & 10.6 & 60 & 45.5 & 58 & 43.9 & \\
\hline stoped & 466 & 34.1 & 47 & 10.1 & 258 & 55.5 & 160 & 34.4 & \\
\hline MEDICATION USE & & & & & & & & & $<.001^{*}$ \\
\hline polypharmacy & 338 & 24.8 & 74 & 34.9 & 193 & 24.5 & 71 & 19.6 & \\
\hline HEALTH RELATED QUALITY OF LIFE & Mean (SD) & & Mean (SD) & & Mean (SD) & & Mean (SD) & & \\
\hline PCS & $46.97(10.16)$ & & $43.52(11.15)$ & & $47.25(9.89)$ & & $48.18(9.81)$ & & $<.001^{* *}$ \\
\hline MCS & $53.20(8.57)$ & & $51.63(9.89)$ & & $53.36(8.12)$ & & $53.70(8.65)$ & & $.030^{* *}$ \\
\hline
\end{tabular}

* Chi-Square for the three categories non-drinking, drinking within the guidelines and risky drinking; ${ }^{* *}$ Anova analyses with Bonferonni correction for the three categories non-drinking, drinking within the guidelines and risky drinking 
Table 2

Prevalence and characteristics of binge drinking among older adults

\begin{tabular}{|c|c|c|c|c|c|}
\hline & no BingeDrink & & BingeDrinking & & \\
\hline & $\mathbf{N}$ & $\%$ & $\mathbf{N}$ & $\%$ & $\mathrm{p}$ \\
\hline TOTAL POPULATION & 1165 & 85.2 & 203 & 14.8 & \\
\hline \multicolumn{6}{|l|}{ DEMOGRAPHICS } \\
\hline GENDER & & & & & $<.001^{*}$ \\
\hline women & 707 & 92.9 & 148 & 7.1 & \\
\hline men & 457 & 75.5 & 54 & 24.5 & \\
\hline AGE & & & & & $<.001^{*}$ \\
\hline young older adults (65-74) & 674 & 81.1 & 157 & 18.9 & \\
\hline older adults (75-84) & 416 & 90.6 & 43 & 9.4 & \\
\hline older old adults (85+) & 74 & 96.1 & 3 & 3.9 & \\
\hline LIVING SITUATION & & & & & $<.001^{*}$ \\
\hline living alone & 92 & 76 & 29 & 24 & \\
\hline with partner & 852 & 84.8 & 153 & 15.2 & \\
\hline widowhood & 215 & 91.5 & 20 & 8.5 & \\
\hline EDUC LEVEL & & & & & $.239^{*}$ \\
\hline primary school or lower & 25 & 92.6 & 2 & 7.4 & \\
\hline lower secondary & 376 & 85.3 & 65 & 14.7 & \\
\hline higher secondary & 416 & 86.8 & 63 & 13.2 & \\
\hline higher education & 345 & 82.7 & 72 & 17.3 & \\
\hline RECENT LOSS & & & & & $.493^{*}$ \\
\hline no & 895 & 84.8 & 160 & 15.2 & \\
\hline yes & 267 & 86.4 & 42 & 13.6 & \\
\hline FAMILY HISTORY OF ALCOHOL PROBLEMS & & & & $.003^{*}$ & \\
\hline no & 947 & 86.6 & 147 & 13.4 & \\
\hline yes & 215 & 79.3 & 56 & 20.7 & \\
\hline \multicolumn{6}{|l|}{ ALCOHOL USE } \\
\hline NIAAA & & & & & $<.001^{*}$ \\
\hline moderate drinkers & 736 & 93.4 & 52 & 6.6 & \\
\hline at risk drinkers & 213 & 58.8 & 149 & 41.2 & \\
\hline \multicolumn{6}{|l|}{ HEALTH RELATED FACT } \\
\hline SMOKING & & & & & $<.001^{*}$ \\
\hline never & 696 & 90.4 & 74 & 9.6 & \\
\hline yes & 91 & 68.9 & 41 & 31.1 & \\
\hline stoped & 378 & 81.1 & 88 & 18.9 & \\
\hline MEDICATION USE & & & & & $<.001^{*}$ \\
\hline polypharmacy & 312 & 26.8 & 30 & 14.8 & \\
\hline HEALTH RELATED QUALITY OF LIFE & Mean (SD) & & Mean (SD) & & \\
\hline PCS & $46.74(10.26)$ & & $48.15(9.64)$ & & $.156^{* *}$ \\
\hline MCS & $53.40(8.37)$ & & $52.11(9.50)$ & & $.090^{* *}$ \\
\hline
\end{tabular}

* Chi-Square; ** Independent Sample t-test

\section{Results}

\section{Sample and population}

A total of 1,366 adults aged 65 and older completed the questionnaire. The mean age of the participants was 73.24 years $(\mathrm{SD}=6.13)$ and $55.8 \%$ were women. The majority were in the age category of 65-74 years $(60.8 \%)$ and were living with a partner $(76 \%)$. Nearly $23 \%$ reported a loss of a loved one significant person in the past 12 months and $20 \%$ reported having a family history of alcohol problems. Almost $10 \%$ reported smoking and $24.8 \%$ reported 
Table 3

Prevalence and characteristics of hazardous drinking (scoring on Mast- $\mathrm{G} \geq 5$ )

\begin{tabular}{|c|c|c|c|c|c|}
\hline & non hazardous (MAST-G score $<5$ ) & hazardous (MAST-G score $\geq 5$ ) & & & \\
\hline & $\mathbf{n}$ & $\%$ & $\mathbf{n}$ & $\%$ & $\mathrm{p}$ \\
\hline TOTAL POPULATION & 942 & 74.6 & 321 & 25.4 & \\
\hline \multicolumn{6}{|l|}{ DEMOGRAPHICS } \\
\hline GENDER & & & & & $<.001^{*}$ \\
\hline women & 572 & 81.4 & 131 & 18.6 & \\
\hline men & 370 & 66.1 & 190 & 33.9 & \\
\hline AGE & & & & & $.001^{*}$ \\
\hline young older adults (65-74) & 549 & 70.9 & 225 & 29.1 & \\
\hline older adults (75-84) & 336 & 80.2 & 83 & 19.8 & \\
\hline older old adults $(85+)$ & 57 & 81.4 & 13 & 18.6 & \\
\hline LIVING SITUATION & & & & & $.374^{*}$ \\
\hline living alone & 76 & 71 & 31 & 29 & \\
\hline with partner & 689 & 74.1 & 241 & 25.9 & \\
\hline widowhood & 171 & 77.7 & 49 & 22.3 & \\
\hline EDUC LEVEL & & & & & $.008^{*}$ \\
\hline primary school or lower & 16 & 64 & 9 & 36 & \\
\hline lower secondary & 308 & 77.8 & 88 & 22.2 & \\
\hline higher secondary & 347 & 77.3 & 102 & 22.7 & \\
\hline higher education & 269 & 69 & 121 & 31.0 & \\
\hline RECENT LOSS & & & & & $.576^{*}$ \\
\hline no & 731 & 75 & 244 & 25 & \\
\hline yes & 209 & 73.3 & 76 & 26.7 & \\
\hline FAMILY HISTORY OF ALCOHOL PROBLEMS & & & & & $<.001^{*}$ \\
\hline no & 774 & 77.2 & 229 & 22.8 & \\
\hline yes & 167 & 64.5 & 92 & 35.5 & \\
\hline \multicolumn{6}{|l|}{ ALCOHOL USE } \\
\hline NIAAA & & & & & $<.001^{*}$ \\
\hline non drinkers & 190 & 94.1 & 12 & 5.9 & \\
\hline moderate drinkers & 584 & 80.8 & 139 & 19.2 & \\
\hline at risk drinkers & 165 & 49.4 & 169 & 50.6 & \\
\hline NIAAA BINGE DRINKING & & & & & $<.001^{*}$ \\
\hline no binge drinking & 867 & 80.7 & 208 & 19.3 & \\
\hline binge drinking & 76 & 40.2 & 113 & 59.8 & \\
\hline \multicolumn{6}{|l|}{ HEALTH RELATED FACT } \\
\hline SMOKING & & & & & $<.001^{*}$ \\
\hline never & 571 & 79.9 & 144 & 20.1 & \\
\hline yes & 67 & 56.8 & 51 & 43.2 & \\
\hline stoped & 305 & 70.8 & 126 & 29.2 & \\
\hline MEDICATION USE & & & & & $.190^{*}$ \\
\hline polypharmacy & 240 & 25.5 & 70 & 22.6 & \\
\hline HEALTH RELATED QUALITY OF LIFE & Mean (SD) & & Mean (SD) & & \\
\hline PCS & $47.24(10.11)$ & & $46.63(9.87)$ & & $.519^{* *}$ \\
\hline MCS & $54.14(7.90)$ & & $51.22(9.90)$ & & $<.001^{* *}$ \\
\hline
\end{tabular}

${ }^{*}$ Chi-square test; ** Independent Sample t-test 
Table 4

Predictors associated with at risk drinking in a drinking population of older adults

\begin{tabular}{|c|c|c|c|c|c|c|}
\hline & & $\frac{\text { OR }}{\operatorname{Exp}(B)}$ & \multicolumn{2}{|c|}{ 95\% CI for $\operatorname{Exp}(B)$} & $\mathbf{p}$ & \multirow{2}{*}{$\begin{array}{c}\text { Nagelkere } \mathbf{R}^{2} \\
.140\end{array}$} \\
\hline & & & & & & \\
\hline Male & & 2.503 & 1.829 & 3.425 & $<.001$ & \\
\hline \multirow[t]{2}{*}{ Age } & reference: older older adults $(85+)$ & & & & .002 & \\
\hline & older adults (75-84) & .522 & .247 & 1.103 & .089 & \\
\hline \multirow[t]{3}{*}{ Educational level } & reference: primary school or lower & & & & .187 & \\
\hline & lower secondary & .402 & .137 & 1.186 & .099 & \\
\hline & higher secondary & .386 & .132 & 1.131 & .083 & \\
\hline Living Situation & living with a partner & 1.187 & .743 & 1.895 & .473 & \\
\hline Recent loss & & .961 & .684 & 1.352 & .821 & \\
\hline Family history of alcohol problems & & .984 & .692 & 1.400 & .929 & \\
\hline \multicolumn{7}{|l|}{ HEALTH RELATED FACTORS } \\
\hline \multirow[t]{3}{*}{ Smoking } & reference: never & & & & .001 & \\
\hline & yes & 2.288 & 1.427 & 3.668 & .001 & \\
\hline & stoped & 1.504 & 1.089 & 2.077 & .013 & \\
\hline Polypharmacy & & .765 & .529 & 1.106 & .154 & \\
\hline PCS & & 1.000 & .985 & 1.016 & .989 & \\
\hline
\end{tabular}

polypharmacy at the time of the assessment. The total sample scored a mean of $46.97(\mathrm{SD}=10.16)$ on PCS and a mean of $53.20(\mathrm{SD}=8.57)$ on MCS of the SF36.

Among the study sample, $84.4 \%$ currently consumed alcohol, $57.8 \%$ reported drinking within the guidelines, $26.6 \%$ at risk drinking (Table 1 ) and $14.8 \%$ binge drinking (Table 2). A smaller percentage of men (10.1\%) were nondrinkers in comparison to female non-drinkers $(20 \%)$. The alcohol use prevalence among younger older adults (65-74 year) was $85.9 \%$ and declined with age. Concerning at risk drinking, more men $(38.4 \%)$ than women $(17.1 \%)$ were at risk drinkers. Of the older older adults (85+) $21.1 \%$ reported at risk drinking. In the category of at risk drinkers, those living alone $(35.5 \%)$, having a higher educational level $(34.1 \%)$ and being a smoker $(43.9 \%)$ were more presented. Of the drinking population, $24.5 \%$ of those drinking within the guidelines and $19.6 \%$ of the at risk drinkers reported polypharmacy. The non-drinkers reported a lower MCS and PCS in comparison to the drinkers within the guidelines and the at risk drinkers (respectively $\mathrm{t}(1150)=3.51, \mathrm{p}=.030$ and $\mathrm{t}(1150)=12.51$, $\mathrm{p}=<.001)$. The effect size between the drinking patterns is very small for PCS as for MCS (Partial Eta Squared $\mathrm{PCS}=.201$ and $\mathrm{MCS}=.006$ ).
Men $(24.5 \%)$ were substantially more likely than women $(7.1 \%)$ to have engaged in binge drinking (Table 2 ). Almost $20 \%$ of the younger cohort (65-74 year) reported binge drinking. Among binge drinkers, more participants were living alone $(24 \%)$ and were having a family history of alcohol problems (20.7\%). In the binge drinking group, $31.1 \%$ reported being a smoker and $14.8 \%$ reported polypharmacy. Considering the HRQL, there are no differences between the binge drinking and non-binge drinking groups regarding PCS and MCS $($ respectively $\mathrm{t}(1156)=-1.70, \mathrm{p}=.156$ and $\mathrm{t}(1156)=1.85$, $\mathrm{p}=.090)$.

Overall, $25.4 \%$ of the total population scored positive on the MAST-G (score $\geq 5$ ) and were categorized as hazardous drinkers (Table 3). Almost 20\% of women and $34 \%$ of men reported hazardous drinking (Table 3 ). The proportion of older adults reporting hazardous drinking declined with age: $29.1 \%$ in the age category 65-74 years scored positive on the MAST-G compared with $19.8 \%$ of their older peers. Furthermore, older adults with higher education $(31 \%)$ and those having a family history of alcohol problems $(35.5 \%)$ reported hazardous drinking. Surprisingly, almost $20 \%$ of the older adults drinking within the guidelines scored positive on the 
Table 5

Predictors associated with Binge drinking in a drinking population of older adults

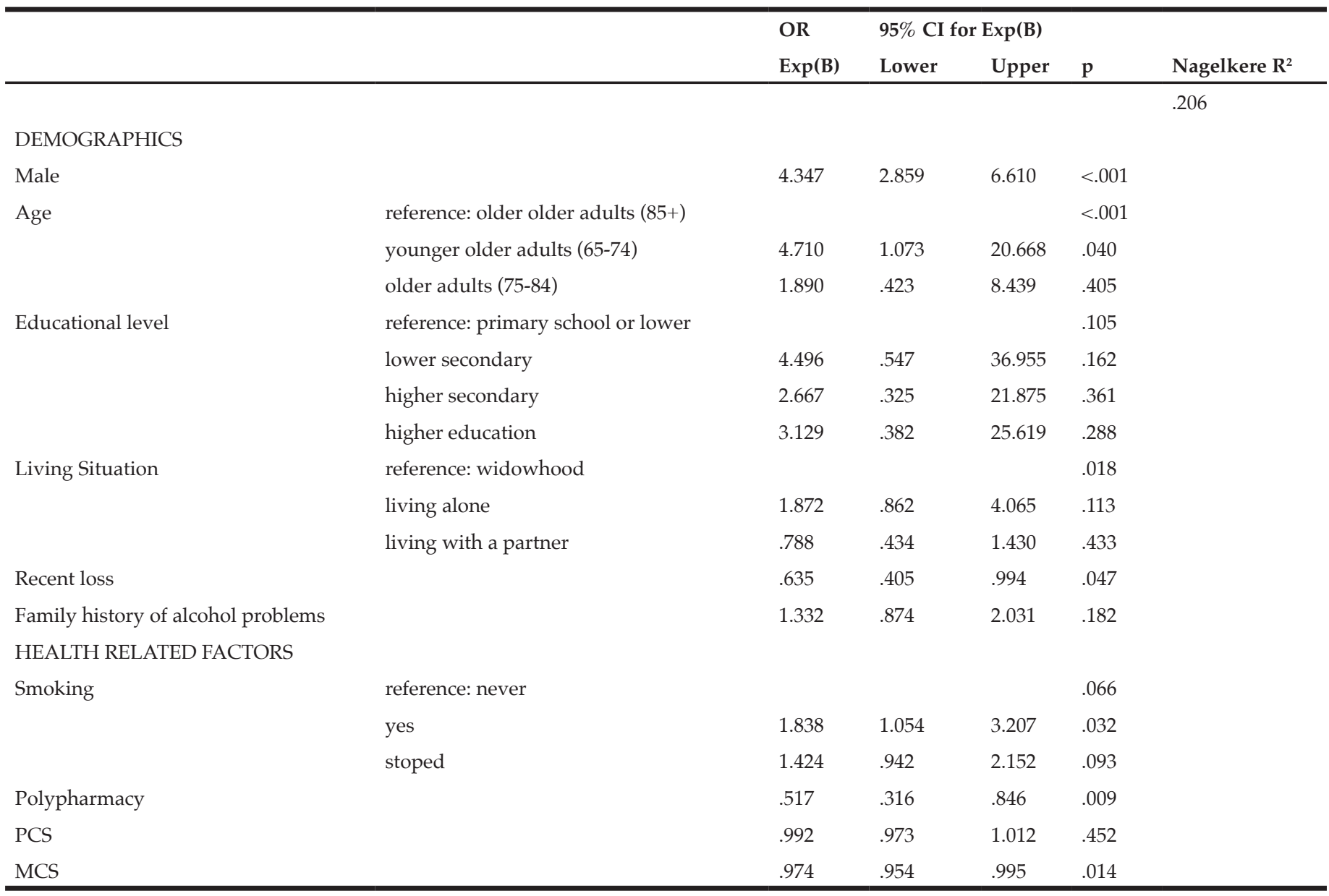

MAST-G. Of the older adults categorized as hazardous drinkers, $43.2 \%$ reported being a smoker and $22.6 \%$ reported polypharmacy. The non-hazardous group scored significantly higher on MCS than the hazardous group $(\mathrm{t}(1067)=4.948, \mathrm{p}=<.001)$. PCS was not significant $(\mathrm{t}(1067)=.877, \mathrm{p}=.519)$.

To examine the predictors of at risk drinking, a multivariate logistic regression analysis was performed on the drinking sample (Table 4). Being male ( $\mathrm{OR}=2.503$, 95\% $\mathrm{CI}=1.829-3.425, \mathrm{p}=<.001)$, living alone $(\mathrm{OR}=2.235$, 95\% $\mathrm{CI}=1.192-4.193, \mathrm{p}=.012)$ and being a smoker $(\mathrm{OR}=2.288,95 \% \mathrm{CI}=1.427-3.668, \mathrm{p}=.001)$ or a former smoker $(\mathrm{OR}=1.504,95 \% \mathrm{CI}=1.089-2.077, \mathrm{p}=.013)$ were associated with at risk drinking.

To examine the predictors of binge drinking, a multivariate logistic regression analysis was performed (Table 5). Being male ( $\mathrm{OR}=4.347,95 \% \mathrm{CI}=2.859-6.610$, $\mathrm{p}=<.001)$, being between 65 and 74 years $(\mathrm{OR}=4.710,95 \%$ $\mathrm{CI}=1.073-20.668, \mathrm{p}=.040)$ and being a smoker $(\mathrm{OR}=1.838$, 95\% $\mathrm{CI}=1.054-3.207, \mathrm{p}=.032)$ were more likely to report binge drinking. Recent loss experience $(\mathrm{OR}=.653,95 \%$ $\mathrm{CI}=.405-.994, \mathrm{p}=.047)$, polypharmacy $(\mathrm{OR}=.517,95 \%$ $\mathrm{CI}=.316-.846, \mathrm{p}=.009)$ and MCS $(\mathrm{OR}=.974,95 \% \mathrm{CI}=.954-$ $.995, \mathrm{p}=.014)$ were inversely associated with binge drinking.

Multivariate logistic regression modelling of hazardous drinking in the drinking sample (Table 6) confirm that being male $(\mathrm{OR}=2.273,95 \% \mathrm{CI}=1.609-3.212, \mathrm{p}=<.001)$ and having a family history of alcohol problems $(\mathrm{OR}=1.629$, 95\% CI=1.136-2.336, $\mathrm{p}=.008)$ were more likely to report hazardous drinking. PCS (OR=.976, 95\% CI=.959-.992, $\mathrm{p}=.004)$ and MCS (OR=.950, 95\% CI=.933-.968, $\mathrm{p}=<.001)$ were inversely associated with hazardous drinking.

\section{Discussion}

Alcohol consumption was high in our sample, suggesting that the trend of increased alcohol use among older adults is also ongoing in our region [3, 29]. This increase might be due to the growing number of healthy life years in combination with a higher average income (3). Furthermore, the commonality of alcohol use in our culture might be extended in this older segment of the population leading to high prevalence of alcohol consumption. In this study, the NIAAA recommendations were used to define at risk alcohol use and binge drinking in older adults. We found a higher prevalence 
Table 6

Predictors associated with hazardous drinking (score $\geq 5$ on MAST-G) in a drinking population of older adults

\begin{tabular}{|c|c|c|c|c|c|c|}
\hline & & \multirow{2}{*}{$\begin{array}{c}\text { OR } \\
\text { Exp(B) }\end{array}$} & \multicolumn{2}{|c|}{$95 \%$ CI for $\operatorname{Exp}(B)$} & \multirow[b]{2}{*}{ p } & \multirow[b]{2}{*}{ Nagelkere $\mathbf{R}^{2}$} \\
\hline & & & Lower & Upper & & \\
\hline & & & & & & .150 \\
\hline \multicolumn{7}{|l|}{ DEMOGRAPHICS } \\
\hline Male & & 2.273 & 1.609 & 3.212 & $<.001$ & \\
\hline \multirow[t]{3}{*}{ Age } & reference: older older adults $(85+)$ & & & & .013 & \\
\hline & younger older adults (65-74) & 2.390 & .930 & 6.139 & .070 & \\
\hline & older adults (75-84) & 1.480 & .574 & 3.813 & .417 & \\
\hline \multirow[t]{4}{*}{ Educational level } & reference: primary school or lower & & & & .052 & \\
\hline & lower secondary & .457 & .143 & 1.459 & .186 & \\
\hline & higher secondary & .363 & .114 & 1.157 & .086 & \\
\hline & higher education & .576 & .180 & 1.840 & .352 & \\
\hline \multirow[t]{3}{*}{ Living Situation } & reference: widowhood & & & & .266 & \\
\hline & living alone & .810 & .407 & 1.615 & .550 & \\
\hline & living with a partner & .683 & .427 & 1.095 & .113 & \\
\hline Recent loss & & .869 & .604 & 1.253 & .453 & \\
\hline Family history of alcohol problems & & 1.629 & 1.136 & 2.336 & .008 & \\
\hline \multicolumn{7}{|l|}{ HEALTH RELATED FACTORS } \\
\hline \multirow[t]{3}{*}{ Smoking } & reference: never & & & & .112 & \\
\hline & yes & 1.609 & .962 & 2.692 & .070 & \\
\hline & stoped & .928 & .650 & 1.323 & .679 & \\
\hline Polypharmacy & & .766 & .517 & 1.136 & .185 & \\
\hline PCS & & .976 & .959 & .992 & .004 & \\
\hline MCS & & .950 & .933 & .968 & $<.001$ & \\
\hline
\end{tabular}

of at risk drinking and binge drinking than expected in a population of 65 years and older $(3,5,19,29,44)$. These results raise concerns for health care systems as older adults are more vulnerable for the adverse consequences of alcohol use, especially when consuming alcohol in amounts exceeding NIAAA recommended guidelines (45).

In the at risk drinking category, being male, younger of age (64-75), living with someone, having a higher education and being a former smoker were more frequently represented. The characteristics of binge drinkers determined in this study were being male, younger age (65-74), living with a partner, having a family history of alcohol problem and being a smoker. These characteristics are in line with previous studies (5, $29,31,44,46,47)$. Younger older adults reporting at risk and binge drinking more often than their older peers might be due to a survival bias. At risk drinkers and binge drinkers either die at younger age or stop alcohol use at younger age due to health complications (22). Older adults exposed to medication and polypharmacy in combination with alcohol use, are more at risk for alcohol related adverse reactions (9). In our sample, a high prevalence was reported in the different drinking patterns. These older adults, even the ones drinking according to the guidelines, are very likely to use alcohol in circumstances that place them at risk. The increased prevalence of medication use and alcohol use among older adults suggests the necessity for awareness of the potential interactions between medication and alcohol.

Regarding HRQL, self-reported at risk drinkers registered better physical and mental HRQL than nondrinkers. Furthermore, there was no differences in HRQL between binge drinkers and non-binge drinkers. The only two studies to our knowledge evaluating the relationship between alcohol consumption and HRQL in older adults failed to find any association $(48,49)$. These results may be due to the fact that the development and recognition of negative consequences of at risk alcohol use among older adults may not yet have fully manifested (48). Because older adults generally drink less, health care providers might be less likely to recognize the adverse consequences of alcohol use in an older population (34). Clearly more information is needed to better understand the association between alcohol use and HRQL among older adults (48). 
The prevalence rate of older adults reporting hazardous drinking is much higher than other studies $(2,5,50)$. A systematic analysis of comparison, however, between all studies is hampered by the different assessment tools for alcohol related problems. This diversity in tools indicates the necessity for more research with more deliberate use of standardised measurements. To date, the MAST-G is the only screening tool for alcohol related problems designed for the older segment of the population. The recognition of the MAST-G as an appropriate instrument for the screening of alcohol related problems in older adults $(5,34)$ might be useful to overcome this issue.

There is a substantial alcohol related harm and health risk in older adults $(2,51)$. In our sample, alcohol consumption in excess of NIAAA guidelines was associated with an elevated risk for hazardous drinking. A large portion of the at risk drinkers and binge drinkers scored positive on the MAST-G demonstrating that these two drinking patterns are very precarious for older adults. Drinking in excess of guidelines might result in higher risks for morbidity, including accidents and mortality because older adults are more vulnerable for the adverse consequences of alcohol mortality (19, $37,52)$. Furthermore, results of a multi-country study indicated that older adults are not sufficiently informed about alcohol use and the effects on their physical and mental health (53). More surprisingly, almost one fifth of the older adults drinking within the guidelines of safe drinking, could be categorized as hazardous drinkers. These results suggest that a large proportion of older adults with a significant amount of alcohol related problems are unlikely to be identified as such by their health care givers if that identification relies only on whether their consumption exceeds the recommended limits. Our results should increase awareness on the need for proper prevention and information about unhealthy alcohol use among older adults.

Our results are relevant for health care givers wishing to help and advice older adults on their at risk and binge drinking behaviour. Inadequate information about which older adults are at high risk for the adverse consequences of alcohol consumption makes it challenging to give advice to older adults that could benefit from such counselling (30). In our drinking sample, being male, living alone and being a smoker of former smoker are predictors for at risk drinking. These findings are in line with previous studies $(6,12,30)$. In addition, binge drinking was associated with being male, being 65-74 years, having a recent loss experience, MCS, being a smoker and polypharmacy. These results may be helpful for health care givers to identify older adults at greater risk for unhealthy drinking habits.

Older adults reporting a significant and harmful amount of alcohol related problems due to their alcohol consumption were categorized as hazardous drinkers. According to multivariate analyses with the sample of drinkers, being male and having a family history of alcohol problems are predictors for hazardous drinking. Higher PCS and MCS were protective factors against hazardous drinking.

\section{Limitations of this study}

Despite the fact that questionnaires have been reported as an accurate and reliable measurement (34) and ensuring anonymity, alcohol use as a topic may still be seen as taboo which may lead to socially desirable answers. Consequently, the results on at risk and binge drinking may be underreported and underestimated. Therefore, we should be careful with the interpretations of these prevalence figures.

The relationship between alcohol patterns, sociodemographic characteristics and alcohol related problems are reported as associations due to the cross-sectional nature of the data. It is not possible to determine causality between the different variables. Neither information on past changes in drinking habits nor a timeline of alcohol use and life events were available. More research on the causality between alcohol use and alcohol related problems with its associated factors is needed. A prospective cohort study seems most appropriate to further study alcohol and its associated factors in this population.

This article has provided an overview of the alcohol use and alcohol related problems and its associated factors among the Flemisch Belgian community dwelling older adults. The high prevalence of alcohol use and alcohol related problems reported in this study is an important issue. Prevalence data concerning alcohol use and alcohol related problems are necessary to understand the drinking patterns of older adults in our country. This is one of the few studies exploring the alcohol use and alcohol related problems of a community dwelling sample of older adults in Belgium. This emphasises the poverty of data concerning alcohol consumption among older adults in our area. An increased attention among public health, care givers and older adults is necessary otherwise at risk alcohol problems in future older generations could be left unnoticed if attention is not given to this issue.

Funding: This research did not receive any grant from funding agencies in the public, commercial, or not-for-profit sectors.

Competing interests: All authors declare that they have no competing interests.

List those individuals who provided help during research: The authors wish to thank all the older adults for participating in this research and all the research assistants for collecting the data.

\section{References}

1. Platt, A., F.A. Sloan, and P. Costanzo, Alcohol-Consumption Trajectories and Associated Characteristics Among Adults Older Than Age 50. Journal of Studies on Alcohol and Drugs, 2010. 71(2): p. 169-179.

2. Moos, R.H., et al., Older Adults' Alcohol Consumption and Late-Life Drinking Problems: A 20-Year Perspective. Addiction (Abingdon, England), 2009. 104(8): p. 1293-1302.

3. Geels, L.M., et al., Increases in alcohol consumption in women and elderly 
groups: evidence from an epidemiological study. BMC Public Health, 2013 13(1): p. 207.

4. Hallgren, M., P. Högberg, and S. Andréasson, Alcohol consumption and harm among elderly Europeans: falling between the cracks. European Journal of Public Health, 2010. 20(6): p. 616-617.

5. Hoeck, S. and G. Van Hal, Unhealthy drinking in the Belgian elderly population: prevalence and associated characteristics. European Journal of Public Health, 2013. 23(6): p. 1069-1075.

6. Immonen, S., J. Valvanne, and K.H. Pitkala, Older adults' own reasoning for their alcohol consumption. International Journal of Geriatric Psychiatry, 2011. 26(11): p. 1169-1176.

7. Aira, M., S. Hartikainen, and R. Sulkava, Community prevalence of alcohol use and concomitant use of medication-a source of possible risk in the elderly aged 75 and older? Int J Geriatr Psychiatry, 2005. 20.

8. Breitling, L., et al., Low-to-moderate alcohol consumption and smoking cessation rates: Retrospective analysis of 4576 elderly ever-smokers. Drug and Alcohol Dependence, 2010. 108(1): p. 122-129.

9. Cousins, G., et al., Potential for alcohol and drug interactions in older adults: evidence from the Irish longitudinal study on ageing. BMC Geriatrics, 2014 14(1): p. 57.

10. Gargiulo, G., et al., Moderate alcohol consumption predicts long-term mortality in elderly subjects with chronic heart failure. The journal of nutrition, health \& aging, 2013. 17(5): p. 480-485.

11. Hallgren, M., P. Hogberg, and S. Andreasson, Alcohol consumption among elderly European Union citizens: health effects, consumption trends and related issues. 2009, Ostersund: Swedish National Institute of Public Health.

12. Merrick, E.L., et al., Unhealthy drinking patterns in older adults: prevalence and associated characteristics. J Am Geriatr Soc, 2008. 56.

13. Sacco, P., K.K. Bucholz, and E.L. Spitznagel, Alcohol Use Among Older Adults in the National Epidemiologic Survey on Alcohol and Related Conditions: A Latent Class Analysis. Journal of Studies on Alcohol and Drugs, 2009. 70(6): p. 829-838.

14. Borok, J., et al., Why do older unhealthy drinkers decide to make changes or not in their alcohol consumption? Data from the Healthy Living as You Age study. J Am Geriatr Soc, 2013. 61(8): p. 1296-302

15. McClure, L.A., et al., Risky drinking in the older population: A comparison of Florida to the rest of the US. Addictive Behaviors, 2013. 38(4): p. 1894-1897.

16. Rehm, J., et al., The relationship between different dimensions of alcohol use and the burden of disease - an update. Addiction, 2017. 112(6): p. 968-1001.

17. Halme, J.T., et al., Alcohol consumption and all-cause mortality among elderly in Finland. Drug and Alcohol Dependence, 2010. 106(2): p. 212-218.

18. NIAAA, Helping patients who drink too much: a Clinician's guide. 2005, US Department of Health and Human Services.

19. Immonen, S., J. Valvanne, and K.H. Pitkala, Prevalence of at-risk drinking among older adults and associated sociodemographic and health-related factors. Journal of Nutrition Health \& Aging, 2011. 15(9): p. 789-794.

20. Leclerc, B.S., et al., A Classification and Regression Tree for Predicting Recurrent Falling among Community-dwelling Seniors Using Home-care Services. Canadian Journal of Public Health / Revue Canadienne de Sante'e Publique, 2009. 100(4): p. 263-267.

21. Ilomäki, J., et al., Alcohol consumption and tobacco smoking among community-dwelling older Australian men: The Concord Health and Ageing in Men Project. Australasian Journal on Ageing, 2014. 33(3): p. 185-192.

22. Kirchner, J.E., et al., Alcohol consumption among older adults in primary care. J Gen Intern Med, 2007. 22.

23. Moos, R.H., et al., Spouses of Older Adults With Late-Life Drinking Problems: Health, Family, and Social Functioning. Journal of Studies on Alcohol and Drugs, 2010. 71(4): p. 506-514

24. Nadkarni, A., et al., The psychological impact of heavy drinking among the elderly on their co-residents: The 10 / 66 group population based survey in the Dominican Republic. Drug and Alcohol Dependence, 2011. 114(1): p. 82-86.

25. Choi, N.G. and D.M. DiNitto, Psychological distress, binge/heavy drinking and gender differences among older adults. Am J Addict, 2011. 20.

26. Immonen, S., J. Valvanne, and K.H. Pitkala, The prevalence of potential alcohol-drug interactions in older adults. Scand J Prim Health Care, 2013. 31.

27. Gilson, K.M., Risky Drinking in Older Adults: Toward Better Awareness and Screening in Clinical Practice. Autralian Clinical Psychologist, 2016. 2(1).

28. Anderson, P., L. Møller, and G. Galea, Alcohol in the European Union: Consumption, harm and policy approaches. 2012, Copenhagen: WHO Regional Office for Europe.
29. Han, B.H., et al., Demographic trends of binge alcohol use and alcohol use disorders among older adults in the United States, 2005-2014. Drug and Alcohol Dependence, 2017. 170(Supplement C): p. 198-207.

30. Barnes, A.J., et al., Prevalence and correlates of at-risk drinking among older adults: the project SHARE study. J Gen Intern Med, 2010. 25.

31. Touvier, M., et al., Demographic, socioeconomic, disease history, dietary and lifestyle cancer risk factors associated with alcohol consumption. International Journal of Cancer, 2014. 134(2): p. 445-459.

32. St. John, P.D., P.R. Montgomery, and S.L. Tyas, Alcohol misuse, gender and depressive symptoms in community-dwelling seniors. International Journa of Geriatric Psychiatry, 2009. 24(4): p. 369-375.

33. Babor, T.F., et al., AUDIT: The Alcohol Use Disorders Identification Test - Guidelines for Use in Primary Care. 2001, Geneva: World Health Organization, Department of Mental Health and Substance Dependence.

34. Blow, F.C., Treatment Improvement Protocol (TIP) Series No. 26. Rockville, MD:U.S. Departement of Health and Human Services, Public Health Service, Substance Abuse and \%ental Health Services Administration, Center for Substance Abuse Treatment. 1998.

35. Beullens, J. and B. Aertgeerts, Screening for alcohol abuse and dependence in older people using DSM criteria: a review. Aging \& Mental Health, 2004. 8(1): p. 76-82.

36. Fiellin, D.A., M. Reid, and P.G. O'Connor, Screening for alcohol problems in primary care: A systematic review. Archives of Internal Medicine, 2000 160(13): p. 1977-1989.

37. Barry, K.L. and F.C. Blow, Drinking Over the Lifespan: Focus on Older Adults. Alcohol Research : Current Reviews, 2016. 38(1): p. 115-120.

38. Ware, J.E. and B. Gandek, Overview of the SF-36 Health Survey and the International Quality of Life Assessment (IQOLA) Project. Journal of Clinical Epidemiology, 1998. 51(11): p. 903-912.

39. Mishra, G.D., R. Hockey, and A.J. Dobson, A comparison of SF-36 summary measures of physical and mental health for women across the life course. Quality of Life Research, 2014. 23(5): p. 1515-1521.

40. Mishra, G.D., et al., How useful are the SF-36 sub-scales in older people? Mokken scaling of data from the HALCyon programme. Quality of Life Research, 2011. 20(7): p. 1005-1010.

41. Brazier, J.E., et al., Validating the SF-36 health survey questionnaire: new outcome measure for primary care. British Medical Journal, 1992. 305(6846): p. $160-164$

42. Masnoon, N., et al., What is polypharmacy? A systematic review of definitions. BMC Geriatrics, 2017. 17(1): p. 230.

43. IBM, C., IBM SPSSS Statistics for Windows, Version 25.0. Armonk, NY. IBM Corp., Released 2017.

44. Blazer, D.G. and L.T. Wu, The epidemiology of at-risk and binge drinking among middle-aged and elderly community adults: National Survey on Drug Use and Health. Am J Psychiatry, 2009. 166.

45. Moore, A.A., et al., Alcohol use, comorbidity, and mortality. J Am Geriatr Soc, 2006. 54.

46. Kaplan, M.S., et al., The association between alcohol use and long-term care placement among older Canadians: A 14-year population-based study. Addictive Behaviors, 2014. 39(1): p. 219-224.

47. Castro-Costa, E., et al., Alcohol consumption in late-life - The first Brazilian National Alcohol Survey (BNAS). Addictive Behaviors, 2008. 33(12): p. 15981601.

48. Martinez, P., et al., Quality of life and social engagement of alcohol abstainers and users among older adults in South Africa. BMC Public Health, 2014 14(1): p. 316.

49. Ortolá, R., et al., Patterns of alcohol consumption and health-related quality of life in older adults. Drug and Alcohol Dependence, 2016. 159: p. 166-173.

50. Lopes, M.A., et al., Prevalence of Alcohol-Related Problems in an Elderly Population and Their Association With Cognitive Impairment and Dementia. Alcoholism: Clinical and Experimental Research, 2010. 34(4): p. 726-733.

51. Wilson, S.R. et al., The Prevalence of Harmful and Hazardous Alcohol Consumption in Older U.S. Adults: Data from the 2005-2008 National Health and Nutrition Examination Survey (NHANES). Journal of General Internal Medicine, 2014. 29(2): p. 312-319.

52. Jeong, H.G., et al., Impact of alcohol use on mortality in the elderly: Results from the Korean Longitudinal Study on Health and Aging. Drug and Alcohol Dependence, 2012. 121(1): p. 133-139.

53. Rundle-Thiele, S., et al., Benchmarking Aclohol Literacy: A Multi Country Study. Modern Managment Review, 2013. 18(20): p. 99-111. 